\title{
Tissue-Resident Natural Killer Cells
}

\author{
Wayne M. Yokoyama, ${ }^{1,2,5}$ Dorothy K. Sojka, ${ }^{2}$ Hui Peng, ${ }^{3}$ and Zhigang Tian ${ }^{3,4}$ \\ ${ }^{1}$ Howard Hughes Medical Institute, Washington University School of Medicine, \\ St. Louis, Missouri 63110 \\ ${ }^{2}$ Rheumatology Division, Department of Medicine, Washington University School of Medicine, \\ St. Louis, Missouri 63110 \\ ${ }^{3}$ Department of Immunology, School of Life Sciences, University of Science and Technology of China, \\ Hefei, Anhui, 230027 China \\ ${ }^{4}$ Hefei National Laboratory for Physical Sciences at Microscale, University of Science and Technology \\ of China, Hefei, Anhui, 230026 China \\ ${ }^{5}$ Correspondence: yokoyama@dom.wustl.edu
}

\begin{abstract}
Natural killer (NK) cells kill infected and tumor cells and produce cytokines that modulate other immune cells. However, most of our current knowledge is derived from investigations of mouse splenic and human peripheral blood NK cells, "conventional" NK cells. Herein we discuss recent studies indicating that the liver contains two subpopulations of NK cells, one of which is liver-resident and bears distinct markers from another liver subpopulation that resembles conventional NK cells. Thus, the liver and potentially other organs contain tissue-resident NK cells that may differ from conventional NK cells in terms of origin, development, and/or function.
\end{abstract}

Natural killer (NK) cells are innate lymphocytes that control tumors and viruses (Vivier et al. 2011; Yokoyama 2013). Unlike other lymphocytes, that is, $T$ and $B$ cells, NK cells classically exert their effector functions without prior sensitization and do not somatically rearrange their receptor genes (Hackett et al. 1986). Instead, NK cells rely on a fixed number of germline-encoded inhibitory and activation receptors capable of recognizing major histone compatibility complex (MHC) Class I (MHC-I), MHC-I-like molecules, and other ligands (Karlhofer et al. 1992; Brown et al. 2001; Iizuka et al. 2003; Lanier 2005; Bryceson and Long 2008). NK-cell effector functions can be triggered by engagement of NK-cell-activation receptors with target-cell-surface ligands, some of which are up-regulated by infected cells or tumors (Arase et al. 2002; Smith et al. 2002; Guerra et al. 2008; Raulet et al. 2013). NK cells also respond to antigen-presenting cell (APC)-derived cytokines, allowing NK cells to mediate early host responses by producing other proinflammatory cytokines that affect other immune cells (Biron et al. 1999; Krug et al. 2004; Moretta et al. 2006). Most of our current knowledge of NK cells, however, is derived from studies of mouse splenic and human peripheral blood NK cells, hereafter referred to as "conventional" NK cells.

NK cells are also present in other tissues and organs. Because this topic has been extensively reviewed recently (Shi et al. 2011), in this treatise, we highlight a few points relevant to recent advances indicating that certain NK-cell subsets can be found to reside in certain tissues and migrate poorly to other anatomic regions, that is, these subsets represent tissue-resident NK cells.

\section{CONVENTIONAL NK-CELL DEVELOPMENT}

Conventional NK cells are derived from precursor cells in the bone marrow (BM) (Yokoyama et al. 2004; Di Santo 2006), where their development can be divided into several steps (Kondo et al. 1997; Rosmaraki et al. 2001; Igarashi et al. 2002). Hematopoietic stem cells (HSCs) become committed to lymphoid lineage, becoming early lymphoid progenitors (ELP; lineage-negative [ $\mathrm{Lin}^{-}$] $\mathrm{CKi}^{-}$ $\mathrm{t}^{\text {high }} \mathrm{Sca}^{+} \mathrm{Flt}^{+}$) (Igarashi et al. 2002) and then common lymphoid progenitors (CLPs; Lin $^{-} \mathrm{cKit}^{\text {low }} \mathrm{Scal}^{\text {low }}$ IL7R $\alpha^{+}$) (Kondo et al. 1997). Expression of CD122 (IL2/IL15R $\beta$ ) traditionally defines the transition from CLPs to NK-cell precursors (NKPs) committed to the NK-cell lineage (Rosmaraki et al. 2001). However, an earlier progenitor $\mathrm{CD} 122^{-}$population (pre-NKP) in the $\mathrm{BM}$ was recently identified $\left(\mathrm{lin}^{-} \mathrm{cKit}^{-} \mathrm{Flk}^{-} \mathrm{CD} 27^{+}\right.$ $\mathrm{CD} 244^{+} \mathrm{IL}^{-7 R \alpha^{+}} \mathrm{CD}^{2} 22^{-}$) (Fathman et al. 2011). When adoptively transferred, these cells gave rise to donor-derived NK cells in the BM, blood, and spleen, but in no other cell lineages. The maturation of NKPs to immature NK (iNK) cells and later to mature (mNK) cells is further characterized by several putative intermediate stages, based on marker expression (Kim et al. 2002). Expression of CD122 on NKPs marks intermediate Stage I, whereas Stage II NK cells express NK1.1, CD94/ NKG2, and NKG2D. During Stages III and IV, immature NK cells express CD117, Ly49 receptors, and integrin $\alpha_{2}$ (DX5). At Stage IV, immature NK cells proliferate. After expansion, iNK cells become mNK cells, expressing high levels of $\mathrm{CD} 11 \mathrm{~b}$ (Mac1), CD43, and effector functions, that is, target killing and cytokine production. The most 
mature BM NK cells resemble the majority of splenic NK cells, although down-regulation of $\mathrm{CD} 27$ on splenic $\mathrm{CD} 11 \mathrm{~b}^{+}$NK cells is associated with further differentiation (Hayakawa and Smyth 2006). Thus, conventional NK cells progress through several steps, akin to T- and B-cell development, en route to becoming phenotypically and functionally mature splenic NK cells (Yokoyama et al. 2004; Di Santo 2006), but it is important to note that these putative developmental stages are largely based on correlating marker expression in vivo.

In vitro differentiation studies indicate that cells with NK-cell phenotype can be derived from BMELPs cultured with certain cytokines (stem cell factor [SCF], Fms-related tyrosine kinase 3 ligand [Flt3L], IL7, and IL15) (Williams et al. 1997, 1999; Roth et al. 2000). However, in the absence of direct contact with BM stromal cells, such as OP9 cells, developing NK cells are relatively immature (Williams et al. 1999, 2000; Roth et al. 2000). Although these earlier in vitro studies need to be reexamined in light of current knowledge of NK-cell differentiation in vivo, these studies indicate that soluble and contact-dependent factors are required for full maturation of conventional NK cells.

\section{NK CELLS IN OTHER ORGANS}

\section{Uterine NK cells}

NK cells are found in high numbers in unusual areas such as the lining of the uterus. Originally described by morphologists as "granulated uterine metrial gland" cells, NK cells are the most abundant leukocyte at the site of embryo implantation, where they can regulate placental vascularization and pregnancy outcomes (Croy 1994; Ashkar et al. 2000; Croy et al. 2006; Moffett and Loke 2006; Hiby et al. 2010; Manaster and Mandelboim 2010; Chakraborty et al. 2011; Madeja et al. 2011). Thus, in certain tissues, NK cells can have more specialized functional roles than have been apparent by study of conventional NK cells.

\section{Lymph Node NK cells}

NK cells are relatively uncommon in lymph nodes (LNs), unlike T and B cells. Although NK cells in LNs expand in number during certain immune conditions, most of this expansion appears to be due to recruitment rather than in situ proliferation. For example, NK cells can be recruited to draining LNs by activated dendritic cells (DCs) (Martin-Fontecha et al. 2004). During orthopoxvirus infection, NK cells are recruited to the draining LN (Parker et al. 2007; Fang et al. 2008; Pak-Wittel et al. 2013). The recruited NK cells resemble splenic NK cells by phenotypic markers; adoptively transferred splenic NK cells also appear in the draining $\mathrm{LN}$ in a pertussis-toxinsensitive manner partially dependent on the chemokine receptor CXCR3 (Pak-Wittel et al. 2013). Recruitment required IFN $\gamma$ because recruitment did not occur in IFN $\gamma$ receptor-deficient mice or when wild-type (WT) mice were administered anti-IFN $\gamma$-neutralizing anti- body. In turn, IFNy induced production of CXCL9 and CXCL10, chemokine ligands for CXCR3. Similarly, NK cells are increased in the peritoneal cavity after intraperitoneal injection of vaccinia virus (Prlic et al. 2005). This expansion is also pertussis-toxin sensitive and occurs with little in situ proliferation, even though there are resident peritoneal NK cells in naive mice (Gonzaga et al. 2011), indicating recruitment of conventional NK cells to peritoneal cavity during infection. Although the chemokines and chemokine receptors involved in peritoneal cavity recruitment have not been elucidated, conventional NK cells can be recruited to LNs and other tissues during immune responses.

\section{Thymic NK cells}

Despite original descriptions of NK cells as being thymus independent, recent studies indicate that the thymus contains an NK-cell subset phenotypically distinct from splenic NK cells (Vosshenrich et al. 2006). These cells are $\mathrm{CD} 127^{+} \mathrm{CD} 69^{\text {high }} \mathrm{Ly} 49^{\text {low }} \mathrm{CD} 11 \mathrm{~b}^{\text {low }}$, as compared with splenic NK cells that are generally $\mathrm{CD} 127^{-} \mathrm{CD} 69^{-}$ Ly $49^{+} \mathrm{CD} 11 \mathrm{~b}^{\text {high }}$. CD127 (IL7 receptor $\alpha$ ) is a particularly good discriminating marker; a small number of CD $127^{+}$NK cells were also found in LNs (17\%) but were unusual $(<5 \%)$ in other organs such as BM, liver, and spleen. The transcription factor GATA-3 is required for the development of these cells because these cells were absent in GATA-3-deficient mice. Moreover, these cells are absent in athymic nude (Foxn1 $1^{-/-}$) mice, and transplanted normal thymi seeded $\mathrm{CD} 127^{+} \mathrm{NK}$ cells into host $\mathrm{LN}$, indicating that a functional thymus is required for their development.

Interestingly, various fetal organs have CLPs that can differentiate into bipotential progenitors ( $\mathrm{T} / \mathrm{NKPs}$ ) that can give rise to T or NK cells (Rodewald et al. 1992; Carlyle et al. 1997; Jaleco et al. 1997; Ikawa et al. 1999; Michie et al. 2000; Douagi et al. 2002). For example, T/ NKPs in the fetal thymus can differentiate into either TCR $\alpha \beta$ T cells or NK cells (Carlyle and Zuniga-Pflucker 1998). In the adult thymus, a subset of double-negative (DN) cells, that is, DN1 $\left(\mathrm{CD} 4^{-} \mathrm{CD} 8^{-} \mathrm{CD} 44^{+} \mathrm{CD} 25^{-}\right)$ cells, contains T/NKPs (Schmitt and Zuniga-Pflucker 2002; Porritt et al. 2004; Schmitt et al. 2004). When DN1 cells were cultured with untransfected OP9 cells, they developed into B and NK1.1 $1^{+}$cells, whereas T cells developed when exposed to Notch-receptor-ligandtransfected OP9 cells (Schmitt and Zuniga-Pflucker 2002; Porritt et al. 2004). Recent experiments showed that $\operatorname{Rag} 1^{-/-} \mathrm{DN} 1$ cells devoid of $\mathrm{CD} 122^{+} \mathrm{NK} 1.1^{+}$cells, adoptively transferred by intrathymic injection, developed into NK1.1 $1^{+}$cells resembling thymic NK cells (Vargas et al. 2011). Furthermore, Rag1 $1^{-/-}$DN1 CD122 ${ }^{+}$ $\mathrm{NK} 1.1^{+}$thymocytes cultured in vitro on irradiated OP9 cells with SCF, Flt3L, IL7, and IL15 acquired thymic NKcell phenotypes. Finally, serial monitoring of the developing thymic NK cells recapitulated the developmental progression of markers observed on BM NK cells in vivo (Kim et al. 2002), validating the usefulness of these mark- 
ers in following NK-cell development in vivo. Thus, thymic NK cells develop from a thymocyte progenitor (DN1) population.

Thymic NK cells are generally less efficient at target killing but are better at producing cytokines as compared with splenic NK cells (Vosshenrich et al. 2006). This functional difference resembles human peripheral blood CD56 ${ }^{\text {bright }} \mathrm{NK}$ cells that do not kill as well and are better at producing cytokines, compared with CD56 ${ }^{\mathrm{dim}} \mathrm{NK}$ cells that comprise the majority of peripheral blood NK cells (Cooper et al. 2001; Vosshenrich et al. 2006). However, it is not yet known whether CD56 ${ }^{\text {high }} \mathrm{NK}$ cells are derived from the thymus. Although the physiological function of thymic NK cells remains unclear, other studies have suggested that developing T cells can be susceptible to attack by NK cells (Schott et al. 2003), presumably by thymic NK cells.

\section{Liver NK cells}

"Pit cells" were first described by electron microscopy (EM) of rat liver in the year following the initial description of NK cells (Herberman et al. 1975; Kiessling et al. 1975; Wisse et al. 1976). The name "pit" was coined for the characteristic cytoplasmic granules resembling grape pits. These cells are found in other species, including humans and mice, and are now known to be NK cells (Kaneda and Wake 1983; Bouwens et al. 1987; Kaneda 1989). Pit cells are physically in the sinusoid lumen, facing the blood, and are associated with sinusoidal endothelial cells and Kupffer cells, the resident liver macrophages (Kaneda 1989; Wisse et al. 1996). A specialized role for pit cells has not been described (Bouwens et al. 1987; Luo et al. 2000; Wiltrout 2000), but liver NK cells have been reported to mediate several different functions relevant to different liver disorders, such as hepatitis and hepatic fibrosis (for review, see Gao et al. 2009).

Other early studies indicated that single-cell suspensions from the liver contain high percentages of NK cells ( $\sim 50 \%$ of lymphocytes) (Crispe 2009 ) that are somewhat different from conventional NK cells. For example, we and other researchers showed that the liver contains a high frequency (up to $50 \%$ ) of NK cells with phenotypic markers characteristic of immature conventional NK cells, such as TNF-related apoptosis-inducing ligand (TRAIL) and absence of DX5 (Kim et al. 2002; Takeda et al. 2005; Gordon et al. 2012), whereas NK cells at other peripheral sites are $\mathrm{TRAIL}^{-} \mathrm{DX}^{+}$and predominantly mature in phenotype. During early life, phenotypically immature NK cells predominate in the liver and spleen (Takeda et al. 2005). After birth, liver NK cells become a stable subpopulation in adult mice, with relatively low steady-state proliferation, whereas the splenic subset declines sharply (Gordon et al. 2012; Wu et al. 2012). Thus, early studies suggested that the liver might contain an organ-resident NK-cell subset, distinguishable from conventional NK cells, perhaps akin to the thymus.

Challenges to identifying such a putative liver-specific NK-cell subpopulation are related to several unique aspects of the liver, including two afferent vascular supplies, and distinctive immunological features (Crispe 2009). Through the portal vein that drains abdominal organs, including the spleen, the liver receives $\sim 75 \%$ of its afferent blood, thereby exposing it to antigens and microbial products from the gastrointestinal tract. This nutrient-rich venous blood mixes in the sinusoids with oxygenated arterial blood from a second afferent vascular source, the hepatic artery. The sinusoids represent a highly fenestrated, low-pressure vascular system containing many innate immune cells. Thus, if the liver contains organ-resident NK cells, they should reside in the sinusoids where they are likely to be mixed with circulating NK cells.

\section{LIVER-RESIDENT NK CELLS}

We recently showed that a subpopulation of NK cells selectively resides in the liver, that is, liver-resident NK cells (Peng et al. 2013). Here we summarize the findings.

Liver NK cells apparently mediate antigen-specific memory-like responses (O'Leary et al. 2006; Paust et al. 2010; Rouzaire et al. 2011). In particular, upon sensitization with haptens, virus-like particles (VLPs), or vaccinia virus, liver, but not splenic, NK cells confer memory-like responses. These responses were first shown by flank skin exposure to haptens (sensitization), a rest period, then reexposure (the challenge) to the specific hapten on the ear, as indicated by swelling, akin to contact hypersensitivity (CHS) (O'Leary et al. 2006). These responses were seen in WT and Rag-deficient mice lacking T and B cells but having NK cells and were absent in $\mathrm{Rag}^{-}$IL2R $\gamma$ chain (common $\gamma$ chain, $\gamma \mathrm{c}$ )-double-deficient mice that lack NK cells. Adoptive transfer of liver, but not splenic, NK cells from sensitized mice to $\operatorname{Rag} 1^{-/-} \gamma c^{-/-}$mice restored CHS but only when challenged with the sensitizing hapten. Finally, the relevant NK cells were found in CHS lesions. Similar studies with other haptens, VLPs, and vaccinia virus from at least two different laboratories indicate that liver, but not splenic, NK cells are responsible for "antigen-specific" memory-like responses.

"Memory" NK cells in the liver express Ly49C/I, CXCR6, and/or Thy1 (O'Leary et al. 2006; Paust et al. 2010; Gillard et al. 2011), molecules also expressed on other cells, including splenic NK cells (Paust and von Andrian 2011; Vivier et al. 2011). The chemokine receptor CXCR6 is expressed on $\sim 35 \%-55 \%$ of liver NK cells and a few splenic NK cells (Paust et al. 2010). CXCR6 deficiency or anti-CXCR6 treatment of $\mathrm{CXCR}^{+}$mice abrogated NK-cell-mediated CHS. Furthermore, CXCR6expressing cells from the liver, but not the spleen, home to the liver, and CXCR6-deficient mice lack normal numbers of liver NK cells. However, $\mathrm{CXCR}^{+}$and $\mathrm{CXCR}^{-}$ liver NK cells both home to the liver, suggesting that CXCR6 is an imperfect marker of liver-resident NK cells and $\mathrm{CXCR}^{+} \mathrm{NK}$ cells reside outside the liver, where they could be "primed" (Paust et al. 2010; Paust and von Andrian 2011). Alternatively, the liver contains mixed populations of NK cells. Therefore, liver NK cells appear capable of memory-like properties against "antigens," but previous studies did not define a pheno- 
type that can unequivocally distinguish them from other NK cells.

Since hepatic, but not splenic, NK cells confer CHS (O'Leary et al. 2006; Paust et al. 2010; Gillard et al. 2011; Rouzaire et al. 2011), we hypothesized that CHS is due to a distinct NK-cell subset present in liver but not spleen. Indeed, a high proportion of liver NK cells are DX5 ${ }^{-}$, which we previously speculated to be an immature population similar to that in BM (Kim et al. 2002). Approximately $50 \%$ of hepatic $\mathrm{NK} 1.1^{+} \mathrm{CD} 3^{-} \mathrm{NK}$ cells were DX5 ${ }^{-}$, which constituted only $\sim 5 \%-8 \%$ of NK cells in other organs (Peng et al. 2013). We isolated these cells from hapten (oxalazone [OXA])-sensitized WT or $\mathrm{Ragl}^{-/-}$mice and adoptively transferred them into congenically marked naive mice. Donor liver DX5 ${ }^{-}$NK cells were found only in host liver, whereas donor liver DX $5^{+}$ NK cells were found in host liver and other organs. Moreover, donor DX $5^{-} \mathrm{NK}$ cells did not become $\mathrm{DX} 5^{+}$or vice versa. At 1 month after transfer, ear challenge with hapten revealed that only liver DX $5^{-} \mathrm{NK}$ cells from sensitized mice could confer CHS, whereas no CHS was seen with liver DX $5^{-} \mathrm{NK}$ cells from naive mice or liver $\mathrm{DX} 5^{+} \mathrm{NK}$ cells from sensitized mice. Thus, liver DX5 $5^{-} \mathrm{NK}$ cells specifically home to the liver are phenotypically stable and specifically confer CHS.

The absence of DX5 is of limited value in identifying a unique NK-cell subpopulation because immature, conventional NK cells are also DX5 ${ }^{-}$. To identify a marker positively associated with liver DX5 ${ }^{-} \mathrm{NK}$ cells, we performed gene expression microarrays of messenger RNA (mRNA) from liver DX5 ${ }^{-} \mathrm{NK}$ cells and other subsets. We then confirmed differential expression by quantitative reverse-transcription polymerase chain reaction (RTPCR) and flow cytometry. Consistent with previous results (Paust et al. 2010; Gillard et al. 2011), we confirmed expression of CXCR6 and Thy1 on a high percentage of liver DX5 ${ }^{-} \mathrm{NK}$ cells, but they were also expressed on conventional DX $5^{+} \mathrm{NK}$ cells in other tissues (Peng et al. 2013). Most importantly, we found that all liver DX5 ${ }^{-}$ NK cells selectively and exclusively expressed CD49a that is not expressed on NK cells from other tissues, including spleen and BM (Fig. 1) (Peng et al. 2013).

To test the role of liver CD49a ${ }^{+}$NK cells in CHS, we performed adoptive transfer experiments (Peng et al.

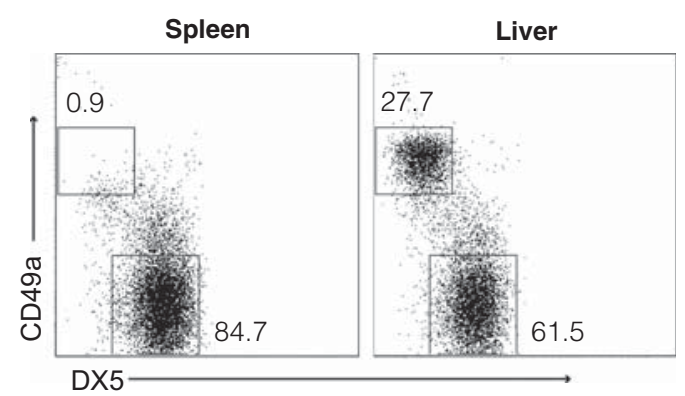

Figure 1. CD49a is expressed on liver $\mathrm{DX} 5^{-} \mathrm{NK} 1.1^{+}$cells. Fluorescence-activated cell sorting (FACS) plots depict $\mathrm{C} 57 \mathrm{BL} / 6 \mathrm{~J}$ cells isolated from the spleen and liver gated on live $\mathrm{CD}^{-}{ }^{-} \mathrm{CD}_{19}{ }^{-} \mathrm{NK} 1.1^{+}$cells. The percentages of $\mathrm{CD}_{4} 9 \mathrm{a}^{+}$ and $\mathrm{DX} 5^{+}$cells are shown.
2013). After challenge, recipients of hepatic CD49a ${ }^{+}$ NK cells from hapten-sensitized mice displayed CHS, whereas mice receiving $\mathrm{CD}_{4} \mathrm{a}^{-} \mathrm{NK}$ cells did not. In addition, the magnitude of ear swelling positively correlated with the number of transferred liver CD49a ${ }^{+} \mathrm{NK}$ cells. When we adoptively transferred hepatic CD49a ${ }^{+} \mathrm{NK}$ cells from OXA- or FITC (fluorescein isothiocyanate)-primed mice, only recipients challenged with the sensitizing hapten displayed CHS. Therefore, hepatic CD49a ${ }^{+} \mathrm{NK}$ cells specifically conferred hapten-specific CHS.

Interestingly, when we stained blood derived from the sinusoids, we detected CD49a ${ }^{+} \mathrm{DX} 5^{-} \mathrm{NK}$ cells that were not in blood obtained from afferent and efferent liver vessels, whereas CD49a ${ }^{-}$DX $5^{+} \mathrm{NK}$ cells were found in all blood sources tested (Fig. 2). To further study liver NK cell trafficking without adoptive transfer, we turned to a parabiosis approach in which surgically conjoined normal mice, distinguished by CD45 allotypes, develop a common circulatory system within a few days (Wright et al. 2001). When there was substantial chimerism of splenic leukocytes, both parabionts had CD49a ${ }^{-} \mathrm{DX} 5^{+}$(conventional) NK cells in their spleens and livers from the other parabiont (Fig. 3; see Peng et al. 2013). In contrast, the liver of each parabiont only had CD $49 \mathrm{a}^{+} \mathrm{DX} 5^{-}$(liver-resident) NK cells of host origin with a few, if any, CD49a ${ }^{+}$ DX $5^{-} \mathrm{NK}$ cells from the other parabiont. Therefore, adoptive transfer, vascular sampling, and parabiosis studies indicate that the liver contains two populations of $\mathrm{NK}$ cells: $\mathrm{CD} 49 \mathrm{a}^{+} \mathrm{DX} 5^{-} \mathrm{NK}$ cells that are stable residents of liver sinusoids and CD49a ${ }^{-} \mathrm{DX} 5^{+} \mathrm{NK}$ cells that are in the circulatory system and pass through the liver under noninflammatory homeostatic conditions.

\section{TISSUE-RESIDENT NK CELLS}

Now that we have established the presence of liverresident NK cells, there are several potential implications of our findings.

1. Other tissues may have tissue-resident NK cells. Here we define tissue-resident NK cells as those that remain in their tissue under steady-state conditions and show minimal tendencies to recirculate. Whereas the adoptive transfer studies showing homing of the cells back to their tissue support this property, these approaches require cellular isolation with $\mathrm{mAbs}$ that could affect cellular migration. More convincing findings are the absence of tissue-resident NK cells in afferent and efferent blood vessels and their presence in the tissue of interest (Peng et al. 2013). Finally, parabiotic mice are extremely useful for showing migratory patterns of potential tissueresident NK cells with minimal manipulation of the cells themselves.

2. Like the liver, other vascular tissues may contain both tissue-resident NK cells and a large pool of circulating "conventional" NK cells. Without markers to distinguish these two subpopulations, analysis of single-cell suspensions of these organs may reveal the summation of distinct populations. 


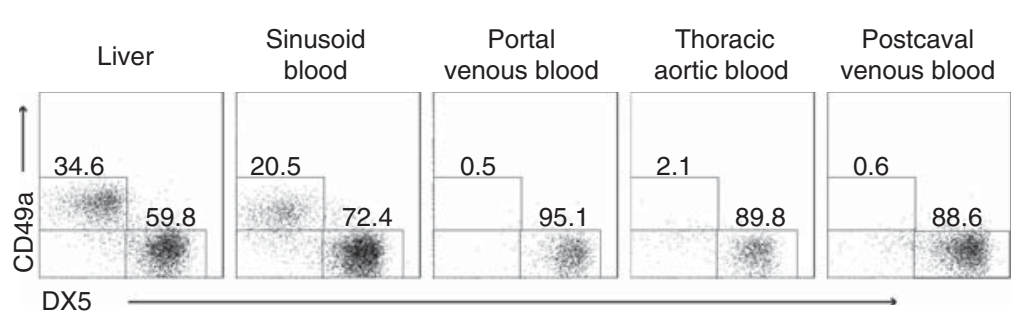

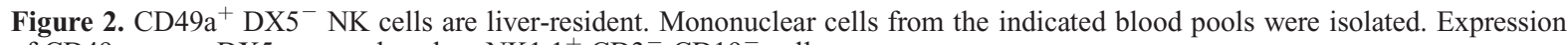
of CD49a versus DX5 was analyzed on NK1.1 $1^{+} \mathrm{CD} 3^{-} \mathrm{CD} 19^{-}$cells.

3. How liver-resident cells are developmentally related to conventional, thymic, and uterine NK cells remains to be determined.

4. Tissue-resident NK cells may express markers that are similar to immature conventional NK cells (Kim et al. 2002; Peng et al. 2013).

a. Tissue-resident NK cells may undergo further maturation, perhaps stimulated by inflammatory conditions, in the tissue of residence, and they may emigrate to become peripheral NK cells. Thymic NK cells reflect one example of this process (Vosshenrich et al. 2006).

b. Alternatively, tissue-resident NK cells could be relatively "mature," and it is misleading to describe them as immature because their development may not be reflected by conventional NK-cell maturation.

c. To distinguish between the above two possibilities, developmental and lineage studies are required to determine whether tissue-resident NK cells share a common progenitor with conventional NK cells or whether they represent distinct lineages. One approach would be to study the role of transcription factors (TFs). A particularly interesting pair of TFs is T-bet (Tbx21) and Eomesodermin (Eomes), which are homologous T-box proteins required for conventional NK-cell development (Townsend et al. 2004; Gordon et al. 2012). Interestingly, Eomes-negative NK cells are enriched in the liver and do not express DXS, although CD49a was not examined (Gordon et al. 2012). On the other hand, these cells expressed T-bet, and Tbx21-/- mice had enrichment of $\mathrm{DX}^{+}{ }^{+} \mathrm{TRAIL}^{-}$NK cells (Gordon et al. 2012), suggesting that $\mathrm{T}$-bet may be required for CD $49 \mathrm{a}^{+} \mathrm{NK}$-cell development but is only partially required for conventional NK-cell development. However, this study is not complete because whether the Tbx21 effect is NK-cell intrinsic or extrinsic was not addressed, and CD49a ${ }^{+}$NK cells were not examined.

5. It is possible that markers that discriminate tissueresident NK cells from conventional NK cells will change during inflammation. Stability of these markers needs to be established.

6. The basis for tissue residency is not entirely clear. For liver-resident NK cells, CXCR6 appears to have role (Paust et al. 2010). However, the mutually exclusive expression of integrins (CD49a, DX5) raises the possibility that they may also be involved. Alternatively, CD49a could be relevant to interactions

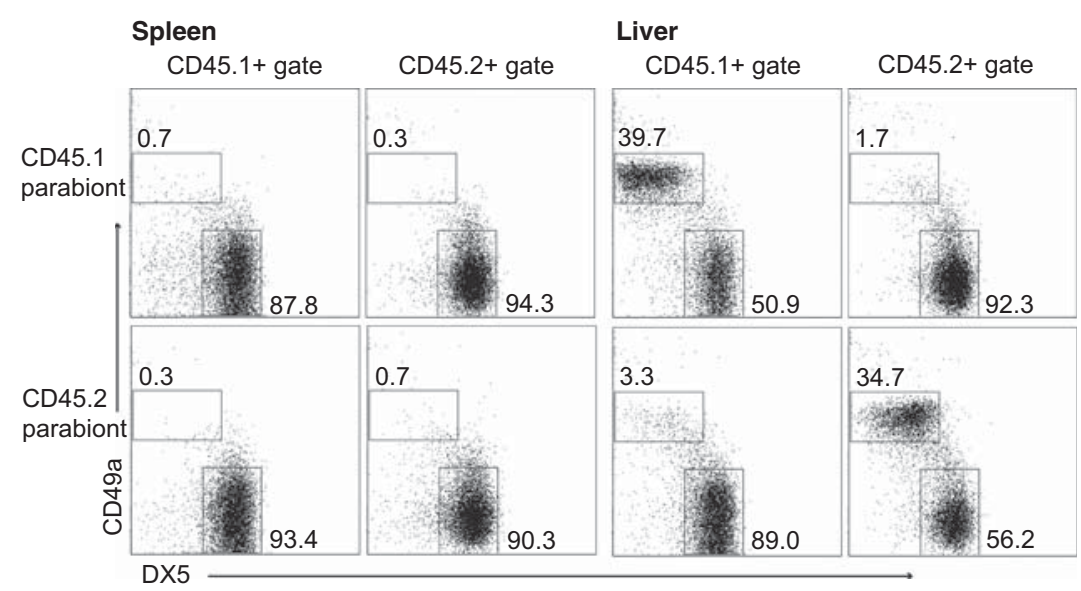

Figure 3. Minimal exchange of CD49a ${ }^{+} \mathrm{DX} 5^{-} \mathrm{NK} 1.1^{+}$cells in parabiotic mice. C57BL/6J (CD45.2) mice were surgically conjoined to congenic B6-Ly5.1 (CD45.1) mice for $14 \mathrm{~d}$, at which time the spleen and liver were harvested for flow cytometry. The FACS dot plots are of the liver and spleen gated on live $\mathrm{CD} 3^{-} \mathrm{CD}^{-} \mathrm{NK} 1.1^{+}$cells followed by a CD45.1 gate (left panels) and CD45.2 gate (right panels) of each parabiont. The percentages of $\mathrm{CD} 49 \mathrm{a}^{+}$and DX-5 $5^{+}$are shown in the dot plots. 
with immune cells in the liver, rather than liver homing per se.

7. During inflammatory processes, tissue-resident NK cells could potentially emigrate to different anatomical regions. Certainly, conventional NK cells can exit the circulatory system, where they normally "reside," and enter LNs, anatomically distinct regions, during inflammatory processes (Pak-Wittel et al. 2013).

8. The developmental origin of tissue-resident NK cells requires additional studies. Our recent studies suggest that progenitors for liver-resident NK cells are still present in the adult liver (Peng et al. 2013). This is somewhat analogous to thymic NK cells, which arise from progenitor cells in the adult thymus.

9. Intriguingly, the fetal liver is the initial site of hematopoiesis, raising the possibility that liver-resident NK-cell progenitors may be seeded early in life. This is akin to other innate cells, such as tissue-resident macrophages that are seeded in early life and self-renew in the adult, independent of circulating monocytes (Schulz et al. 2012; Hashimoto et al. 2013).

10. Liver-resident NK cells may have specialized functions, akin to uNK cells (Croy et al. 2006). Liver NK cells have been implicated in a wide variety of different pathological processes such as liver fibrosis and regeneration, hepatitis, and pathogen defense as well as tumor surveillance of primary liver cancer and metastatic disease (Gao et al. 2009). Whether these functions are mediated by liver-resident or conventional NK cells requires further examination.

11. Studies of "memory" liver NK cells led us to discover liver-resident NK cells. NK-cell memory remains a controversial topic because it is not yet clear how NK cells could recognize a wide variety of "antigens" without somatic rearrangement, and the assays for memory effects are largely based on skin inflammation as measured by differential skin thickness (between solvent alone and hapten dissolved in solvent) (O'Leary et al. 2006; Paust et al. 2010; Gillard et al. 2011). Published studies now indicate that NK memory-like effects are evident in FACS-based CD107a degranulation assays and, importantly, differences in survival (although modest) from viral challenge (Paust et al. 2010; Gillard et al. 2011). However, we have had difficulty repeating the CD107a assays. Further advancements in this area will require robust, highly reproducible, and quantitative assays for memory. Nonetheless, the apparent involvement of liver-resident NK cells in CHS suggests alternative views on how these NK cells are "primed," potentially in the liver itself, rather than in a draining LN akin to T-cell priming, as previously proposed (Paust and von Andrian 2011).

12. Tissue-resident NK cells may interact specifically with other tissue-resident immune cells, as suggested by EM studies of pit cells, which are likely to be liver-resident NK cells (Wisse et al. 1976; Kaneda 1989). Pit cells are often found adjacent to Kupffer cells. These interactions may be critical to the inherent functions of each tissue-resident immune cell.

\section{CONCLUSIONS}

Here, we have attempted to build a case to reconsider NK cells in a different light. Our studies, and those of other researchers, now indicate that the liver normally contains two populations of NK cells: one that is resident in the liver and the other that is present in the circulatory system and is passing through the liver. The liver-resident NK cells have distinct features, suggesting that they may have different functions from conventional NK cells and may have a role in liver diseases. Their developmental pathways may differ somewhat to establish their anatomical niche. Finally, our studies suggest that emerging principles regarding these cells could be applied to NK cells in other tissues.

\section{ACKNOWLEDGMENTS}

Work in the Yokoyama laboratory is supported by the Howard Hughes Medical Institute. D.K. Sojka is supported by Training in Cancer Biology grant T32CA009547. Work in the Tian laboratory is supported by grants from the National Basic Research Project (973 project) (2013CB944902) and the Natural Science Foundation of China (31021061, 91029303). We thank Beatrice Plougastel for helpful discussions, Liping Yang for technical help with parabiosis experiments, and members of the Tian and Yokoyama laboratories for experimental support and insightful dialogues.

\section{REFERENCES}

Arase H, Mocarski ES, Campbell AE, Hill AB, Lanier LL. 2002. Direct recognition of cytomegalovirus by activating and inhibitory NK cell receptors. Science 296: 1323-1326.

Ashkar AA, Di Santo JP, Croy BA. 2000. Interferon gamma contributes to initiation of uterine vascular modification, decidual integrity, and uterine natural killer cell maturation during normal murine pregnancy. J Exp Med 192: 259-270.

Biron CA, Nguyen KB, Pien GC, Cousens LP, Salazar-Mather TP. 1999. Natural killer cells in antiviral defense: Function and regulation by innate cytokines. Annu Rev Immunol 17: $189-220$.

Bouwens L, Remels L, Baekeland M, Van Bossuyt H, Wisse E. 1987. Large granular lymphocytes or "pit cells" from rat liver: Isolation, ultrastructural characterization and natural killer activity. Eur J Immunol 17: 37-42.

Brown MG, Dokun AO, Heusel JW, Smith HR, Beckman DL, Blattenberger EA, Dubbelde CE, Stone LR, Scalzo AA, Yokoyama WM. 2001. Vital involvement of a natural killer cell activation receptor in resistance to viral infection. Science 292: 934-937.

Bryceson YT, Long EO. 2008. Line of attack: NK cell specificity and integration of signals. Curr Opin Immunol 20: $344-$ 352.

Carlyle JR, Zuniga-Pflucker JC. 1998. Requirement for the thymus in alphabeta T lymphocyte lineage commitment. Immunity 9: 187-197.

Carlyle JR, Michie AM, Furlonger C, Nakano T, Lenardo MJ, Paige CJ, Zuniga-Pflucker JC. 1997. Identification of a novel 
developmental stage marking lineage commitment of progenitor thymocytes. J Exp Med 186: 173-182.

Chakraborty D, Rumi MA, Konno T, Soares MJ. 2011. Natural killer cells direct hemochorial placentation by regulating hypoxia-inducible factor dependent trophoblast lineage decisions. Proc Natl Acad Sci 108: 16295-16300.

Cooper MA, Fehniger TA, Turner SC, Chen KS, Ghaheri BA, Ghayur T, Carson WE, Caligiuri MA. 2001. Human natural killer cells: A unique innate immunoregulatory role for the CD56(bright) subset. Blood 97: 3146-3151.

Crispe IN. 2009. The liver as a lymphoid organ. Annu Rev Immunol 27: 147-163.

Croy BA. 1994. Granulated metrial gland cells: Hypotheses concerning possible functions during murine gestation. $J$ Reprod Immunol 27: 85-94.

Croy BA, van den Heuvel MJ, Borzychowski AM, Tayade C. 2006. Uterine natural killer cells: A specialized differentiation regulated by ovarian hormones. Immunol Rev 214: 161 185

Di Santo JP. 2006. Natural killer cell developmental pathways: A question of balance. Annu Rev Immunol 24: 257-286.

Douagi I, Colucci F, Di Santo JP, Cumano A. 2002. Identification of the earliest prethymic bipotent $\mathrm{T} / \mathrm{NK}$ progenitor in murine fetal liver. Blood 99: 463-471.

Fang M, Lanier LL, Sigal LJ. 2008. A role for NKG2D in NK cell-mediated resistance to poxvirus disease. PLoS Pathog 4: e30.

Fathman JW, Bhattacharya D, Inlay MA, Seita J, Karsunky H, Weissman IL. 2011. Identification of the earliest natural killer cell-committed progenitor in murine bone marrow. Blood 118: $5439-5447$.

Gao B, Radaeva S, Park O. 2009. Liver natural killer and natural killer T cells: Immunobiology and emerging roles in liver diseases. J Leukoc Biol 86: 513-528

Gillard GO, Bivas-Benita M, Hovav AH, Grandpre LE, Panas MW, Seaman MS, Haynes BF, Letvin NL. 2011. Thy1+ NK cells from vaccinia virus-primed mice confer protection against vaccinia virus challenge in the absence of adaptive lymphocytes. PLoS Pathog 7: e1002141.

Gonzaga R, Matzinger P, Perez-Diez A. 2011. Resident peritoneal NK cells. J Immunol 187: 6235-6242.

Gordon SM, Chaix J, Rupp LJ, Wu J, Madera S, Sun JC, Lindsten T, Reiner SL. 2012. The transcription factors T-bet and Eomes control key checkpoints of natural killer cell maturation. Immunity 36: 55-67.

Guerra N, Tan YX, Joncker NT, Choy A, Gallardo F, Xiong N, Knoblaugh S, Cado D, Greenberg NM, Raulet DH. 2008 NKG2D-deficient mice are defective in tumor surveillance in models of spontaneous malignancy. Immunity 28: 571580.

Hackett J Jr, Bosma GC, Bosma MJ, Bennett M, Kumar V. 1986. Transplantable progenitors of natural killer cells are distinct from those of T and B lymphocytes. Proc Natl Acad Sci 83: 3427-3431.

Hashimoto D, Chow A, Noizat C, Teo P, Beasley MB, Leboeuf M, Becker CD, See P, Price J, Lucas D, et al. 2013. Tissueresident macrophages self-maintain locally throughout adult life with minimal contribution from circulating monocytes. Immunity 38: 792-804.

Hayakawa Y, Smyth MJ. 2006. CD27 dissects mature NK cells into two subsets with distinct responsiveness and migratory capacity. J Immunol 176: 1517-1524.

Herberman RB, Nunn ME, Lavrin DH. 1975. Natural cytotoxic reactivity of mouse lymphoid cells against syngeneic and allogeneic tumors. I. Distribution of reactivity and specificity. Int J Cancer 16: 216.

Hiby SE, Apps R, Sharkey AM, Farrell LE, Gardner L, Mulder A, Claas FH, Walker JJ, Redman CW, Morgan L, et al. 2010. Maternal activating KIRs protect against human reproductive failure mediated by fetal HLA-C2. J Clin Invest 120: $4102-$ 4110.

Igarashi H, Gregory SC, Yokota T, Sakaguchi N, Kincade PW. 2002. Transcription from the RAG1 locus marks the earliest lymphocyte progenitors in bone marrow. Immunity 17: 117130.

Iizuka K, Naidenko OV, Plougastel BF, Fremont DH, Yokoyama WM. 2003. Genetically linked C-type lectin-related ligands for the NKRP1 family of natural killer cell receptors. Nat Immunol 4: 801-807.

Ikawa T, Kawamoto H, Fujimoto S, Katsura Y. 1999. Commitment of common $\mathrm{T} /$ Natural killer (NK) progenitors to unipotent $\mathrm{T}$ and $\mathrm{NK}$ progenitors in the murine fetal thymus revealed by a single progenitor assay. $J$ Exp Med 190: $1617-$ 1626.

Jaleco AC, Blom B, Res P, Weijer K, Lanier LL, Phillips JH, Spits H. 1997. Fetal liver contains committed NK progenitors, but is not a site for development of CD34+ cells into T cells. J Immunol 159: 694-702.

Kaneda K. 1989. Liver-associated large granular lymphocytes: Morphological and functional aspects. Arch Histol Cytol 52: 447-459.

Kaneda K, Wake K. 1983. Distribution and morphological characteristics of the pit cells in the liver of the rat. Cell Tissue Res 233: 485-505.

Karlhofer FM, Ribaudo RK, Yokoyama WM. 1992. MHC class I alloantigen specificity of Ly-49+ IL-2-activated natural killer cells. Nature 358: $66-70$.

Kiessling R, Klein E, Wigzell H. 1975. Natural killer cells in the mouse. I. Cytotoxic cells with specificity for mouse Moloney leukemia cells: Specificity and distribution according to genotype. Eur J Immunol 5: 112-117.

Kim S, Iizuka K, Kang HS, Dokun A, French AR, Greco S, Yokoyama WM. 2002. In vivo developmental stages in murine natural killer cell maturation. Nature Immunol 3: 523528 .

Kondo M, Weissman IL, Akashi K. 1997. Identification of clonogenic common lymphoid progenitors in mouse bone marrow. Cell 91: 661-672.

Krug A, French AR, Barchet W, Fischer JAA, Dzionek A, Pingel JT, Orihuela MM, Akira S, Yokoyama WM, Colonna M. 2004. TLR9-dependent recognition of MCMV by IPC and DC generates coordinated cytokine responses that activate antiviral NK cell function. Immunity 21: 107-119.

Lanier LL. 2005. NK cell recognition. Annu Rev Immunol 23: $225-274$

Luo DZ, Vermijlen D, Ahishali B, Triantis V, Plakoutsi G, Braet F, Vanderkerken K, Wisse E. 2000. On the cell biology of pit cells, the liver-specific NK cells. World J Gastroenterol 6: $1-11$.

Madeja Z, Yadi H, Apps R, Boulenouar S, Roper SJ, Gardner L, Moffett A, Colucci F, Hemberger M. 2011. Paternal MHC expression on mouse trophoblast affects uterine vascularization and fetal growth. Proc Natl Acad Sci 108: 4012-4017.

Manaster I, Mandelboim O. 2010. The unique properties of uterine NK cells. Am J Reprod Immunol 63: 434-444.

Martin-Fontecha A, Thomsen LL, Brett S, Gerard C, Lipp M, Lanzavecchia A, Sallusto F. 2004. Induced recruitment of NK cells to lymph nodes provides IFN-gamma for $\mathrm{T}(\mathrm{H}) 1$ priming. Nat Immunol 5: 1260-1265.

Michie AM, Carlyle JR, Schmitt TM, Ljutic B, Cho SK, Fong Q, Zuniga-Pflucker JC. 2000. Clonal characterization of a bipotent $\mathrm{T}$ cell and NK cell progenitor in the mouse fetal thymus. J Immunol 164: 1730-1733.

Moffett A, Loke C. 2006. Immunology of placentation in eutherian mammals. Nat Rev Immunol 6: 584-594.

Moretta L, Ferlazzo G, Bottino C, Vitale M, Pende D, Mingari MC, Moretta A. 2006. Effector and regulatory events during natural killer-dendritic cell interactions. Immunol Rev 214: 219-228.

O'Leary JGO, Goodarzi M, Drayton DL, von Andrian UH. 2006. T and B cell-independent adaptive immunity mediated by natural killer cells. Nat Immunol 7: 507-516.

Pak-Wittel MA, Yang L, Sojka DK, Rivenbark JG, Yokoyama WM. 2013. Interferon-gamma mediates chemokine-dependent recruitment of natural killer cells during viral infection. Proc Natl Acad Sci 110: E50-E59. 
Parker AK, Parker S, Yokoyama WM, Corbett JA, Buller RM. 2007. Induction of natural killer cell responses by ectromelia virus controls infection. $J$ Virol 81: 4070-4079.

Paust S, von Andrian UH. 2011. Natural killer cell memory. Nat Immunol 12: 500-508.

Paust S, Gill HS, Wang BZ, Flynn MP, Moseman EA, Senman B, Szczepanik M, Telenti A, Askenase PW, Compans RW, et al. 2010. Critical role for the chemokine receptor CXCR6 in NK cell-mediated antigen-specific memory of haptens and viruses. Nat Immunol 11: 1127-1135.

Peng H, Jiang X, Chen Y, Sojka DK, Wei H, Gao X, Sun R, Yokoyama WM, Tian Z. 2013. Liver-resident NK cells confer adaptive immunity in skin-contact inflammation. $J$ Clin Invest 123: $1444-1456$.

Porritt HE, Rumfelt LL, Tabrizifard S, Schmitt TM, ZunigaPflucker JC, Petrie HT. 2004. Heterogeneity among DN1 prothymocytes reveals multiple progenitors with different capacities to generate $\mathrm{T}$ cell and non-T cell lineages. Immunity 20: 735-745.

Prlic M, Gibbs J, Jameson SC. 2005. Characteristics of NK cell migration early after vaccinia infection. JImmunol 175: 2152 2157.

Raulet DH, Gasser S, Gowen BG, Deng W, Jung H. 2013. Regulation of ligands for the NKG2D activating receptor. Annu Rev Immunol 31: 413-441.

Rodewald HR, Moingeon P, Lucich JL, Dosiou C, Lopez P, Reinherz EL. 1992. A population of early fetal thymocytes expressing Fc gamma RII/III contains precursors of T lymphocytes and natural killer cells. Cell 69: 139-150.

Rosmaraki EE, Douagi I, Roth C, Colucci F, Cumano A, Di Santo JP. 2001. Identification of committed NK cell progenitors in adult murine bone marrow. Eur J Immunol 31: 19001909.

Roth C, Carlyle JR, Takizawa H, Raulet DH. 2000. Clonal acquisition of inhibitory Ly49 receptors on developing NK cells is successively restricted and regulated by stromal class I MHC. Immunity 13: 143-153.

Rouzaire P, Luci C, Blasco E, Bienvenu J, Walzer T, Nicolas JF, Hennino A. 2011. Natural killer cells and T cells induce different types of skin reactions during recall responses to haptens. Eur J Immunol 42: 80-88.

Schmitt TM, Zuniga-Pflucker JC. 2002. Induction of T cell development from hematopoietic progenitor cells by deltalike-1 in vitro. Immunity 17: 749-756.

Schmitt TM, Ciofani M, Petrie HT, Zuniga-Pflucker JC. 2004. Maintenance of $\mathrm{T}$ cell specification and differentiation requires recurrent notch receptor-ligand interactions. $J$ Exp Med 200: 469-479.

Schott E, Bonasio R, Ploegh HL. 2003. Elimination in vivo of developing T cells by natural killer cells. J Exp Med 198: 1213-1224.

Schulz C, Gomez Perdiguero E, Chorro L, Szabo-Rogers H, Cagnard N, Kierdorf K, Prinz M, Wu B, Jacobsen SE, Pollard JW, et al. 2012. A lineage of myeloid cells independent of Myb and hematopoietic stem cells. Science 336: 86-90.

Shi FD, Ljunggren HG, La Cava A, Van Kaer L. 2011. Organspecific features of natural killer cells. Nat Rev Immunol 11: 658-671.
Smith HR, Heusel JW, Mehta IK, Kim S, Dorner BG, Naidenko OV, Iizuka K, Furukawa H, Beckman DL, Pingel JT, et al. 2002. Recognition of a virus-encoded ligand by a natural killer cell activation receptor. Proc Natl Acad Sci 99: 8826-8831.

Takeda K, Cretney E, Hayakawa Y, Ota T, Akiba H, Ogasawara K, Yagita H, Kinoshita K, Okumura K, Smyth MJ. 2005. TRAIL identifies immature natural killer cells in newborn mice and adult mouse liver. Blood 105: 2082-2089.

Townsend MJ, Weinmann AS, Matsuda J, Saloman R, Farnham P, Biron CA, Gapin L, Glimcher LH. 2004. T-bet regulates the terminal maturation and homeostasis of NK and Va14i NKT cells. Immunity 20: 477-494.

Vargas CL, Poursine-Laurent J, Yang L, Yokoyama WM. 2011. Development of thymic NK cells from double-negative 1 thymocyte precursors. Blood 118: 3570-3578.

Vivier E, Raulet DH, Moretta A, Caligiuri MA, Zitvogel L, Lanier LL, Yokoyama WM, Ugolini S. 2011. Innate or adaptive immunity? The example of natural killer cells. Science 331: $44-49$.

Vosshenrich CA, Garcia-Ojeda ME, Samson-Villeger SI, Pasqualetto V, Enault L, Richard-Le Goff O, Corcuff E, GuyGrand D, Rocha B, Cumano A, et al. 2006. A thymic pathway of mouse natural killer cell development characterized by expression of GATA-3 and CD127. Nat Immunol 7: 12171224.

Williams NS, Moore TA, Schatzle JD, Puzanov IJ, Sivakumar PV, Zlotnik A, Bennett M, Kumar V. 1997. Generation of lytic natural killer 1.1+, Ly-49- cells from multipotential murine bone marrow progenitors in a stroma-free culture: Definition of cytokine requirements and developmental intermediates. J Exp Med 186: 1609-1614.

Williams NS, Klem J, Puzanov IJ, Sivakumar PV, Bennett M, Kumar V. 1999. Differentiation of NK1.1+, Ly49+ NK cells from flt $3+$ multipotent marrow progenitor cells. J Immunol 163: $2648-2656$.

Williams NS, Kubota A, Bennett M, Kumar V, Takei F. 2000. Clonal analysis of NK cell development from bone marrow progenitors in vitro: Orderly acquisition of receptor gene expression. Eur J Immunol 30: 2074-2082.

Wiltrout RH. 2000. Regulation and antimetastatic functions of liver-associated natural killer cells. Immunol Rev 174: 63-76.

Wisse E, van't Noordende JM, van der Meulen J, Daems WT. 1976. The pit cell: Description of a new type of cell occurring in rat liver sinusoids and peripheral blood. Cell Tissue Res 173: 423-435.

Wisse E, Braet F, Luo D, De Zanger R, Jans D, Crabbe E, Vermoesen A. 1996. Structure and function of sinusoidal lining cells in the liver. Toxicol Pathol 24: 100-111.

Wright DE, Wagers AJ, Gulati AP, Johnson FL, Weissman IL. 2001. Physiological migration of hematopoietic stem and progenitor cells. Science 294: 1933-1936.

Wu X, Chen Y, Wei H, Sun R, Tian Z. 2012. Development of murine hepatic NK cells during ontogeny: Comparison with spleen NK cells. Clin Dev Immunol 2012: 759765.

Yokoyama WM. 2013. Chapter 17. Natural killer cells. in Fundamental immunology (ed. Paul WE), pp. 395-431. Lippincott Williams \& Wilkins, Philadelphia.

Yokoyama WM, Kim S, French AR. 2004. The dynamic life of natural killer cells. Annu Rev Immunol 22: 405-429. 


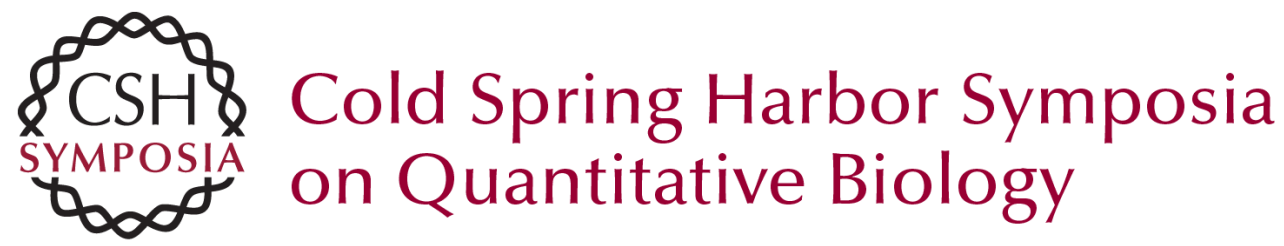

\section{Tissue-Resident Natural Killer Cells}

Wayne M. Yokoyama, Dorothy K. Sojka, Hui Peng, et al.

Cold Spring Harb Symp Quant Biol 2013 78: 149-156 originally published online February 28, 2014

Access the most recent version at doi:10.1101/sqb.2013.78.020354

References This article cites 79 articles, 28 of which can be accessed free at: http://symposium.cshlp.org/content/78/149.full.html\#ref-list-1

\section{License}

Email Alerting

Service

Receive free email alerts when new articles cite this article - sign up in the box at the top right corner of the article or click here. 